\title{
Редкоземельный потенциал апатита в месторождениях и отходах производства апатито-нефелиновых руд Хибинского массива
}

\author{
Когарко Л.Н. \\ Институт геохимии и аналитической химии им. В.И. Вернадского PAH, Москва, kogarko@geokhi.ru
}

Аннотация. Хибины - одна из крупнейших щелочных интрузий мира, включает гигантские апатитовые месторождения. Апатит представлен F-апатитом и содержит исключительно высокую концентрацию $\mathrm{SrO}$ (4,5 мас. \% в среднем) и повышенные содержания редкоземельных элементов (РЗЭ до 8891 ppm).

Отсутствие европиевой аномалии предполагает остаточный характер хибинской щелочной магмы и указывает на то, что дифференциация первичной оливин-меланефелинитовой магмы развивалась без фракционирования плагиоклаза, который является основным минералом-концентратором $\mathrm{Sr}$ и Eu в базальтовых магматических системах.

Проведена оценка редкоземельного потенциала отходов производства апатито-нефелиновых руд Хибинского массива. На основании полученных данных по содержаниям редких земель, общее содержание редкоземельных металлов в отходах составляют около 1,0-1,6 млн тонн. Таким образом, в отходах переработки апатито-нефелиновых руд содержаться довольно высокие содержания редкоземельных металлов.

Ключевые слова: апатит; Хибины; апатит-нефелиновое месторождение; фазовая диаграмма апатитнефелин-диопсид.

\section{Rare-earth potential of Apatite in deposits and wastes of production of Apatite-nepheline ores of the Khibiny massif}

\author{
Kogarko L.N. \\ Vernadsky Institute of Geochemistry and Analytical Chemistry, RAS, Moscow,kogarko@geokhi.ru
}

\begin{abstract}
Khibiny, one of the world's largest peralkaline intrusions, hosts gigantic apatite deposits. Apatite is represented by F-apatite and it contains exceptionally high concentration of SrO. (4.5 wt \% on average) and increased amounts of rare earth elements (REEs; up to $8891 \mathrm{ppm}$ ).

Negative Eu anomaly signature of apatite suggests a residual character of the Khibiny alkaline magma, and it indicates that the differentiation of the primary olivine-melanephelinitic magma developed without fractionation of plagioclase, which is the main mineral-concentrator of $\mathrm{Sr}$ and $\mathrm{Eu}$ in basaltic magmatic systems.

The estimation of rare-earth potential of apatite-nepheline ore production wastes of the Khibiny massif is carried out. According to the data on the content of rare earths, total content of rare earth metals in waste is about 1.0-1.6 million tons. Thus, waste processing of apatite-nepheline ores contain quite high concentration of rare earth metals.
\end{abstract}

Key words: apatite; Khibiny; apatite-nepheline deposit; phase diagram apatite-nepheline-diopside.

В настоящее время апатито-нефелиновые месторождения Кольского полуострова (Хибинский массив) занимают ведущее место в структуре сырьевой базы России-источник фосфора, алюминия, стронция, рубидия, галлия и редких земель. Важной задачей является исследование распределения редких земель и других примесей в апатитовых рудах месторождений, а также оценка редкоземельного потенциала отходов производства апатитового концентрата. Эти работы позволят на современном уровне оценить редкоземельный потенциал апатитовых руд Российской Арктики, а также количественно оценить их комплексный характер и редкоземельный потенциал производственных отходов.

Сегодня ряд западных стран закупает Хибинский апатитовый концентрат не столько для извлечения фосфора, сколько для получения редкоземельных металлов. Предприятия нашей страны пока не имеют высокопродуктивных технологий. Сейчас из-за отсутствия подходящих рентабельных технологий задерживается освоение одного из лучших мировых месторождений с высоким содержанием Р3Э. 


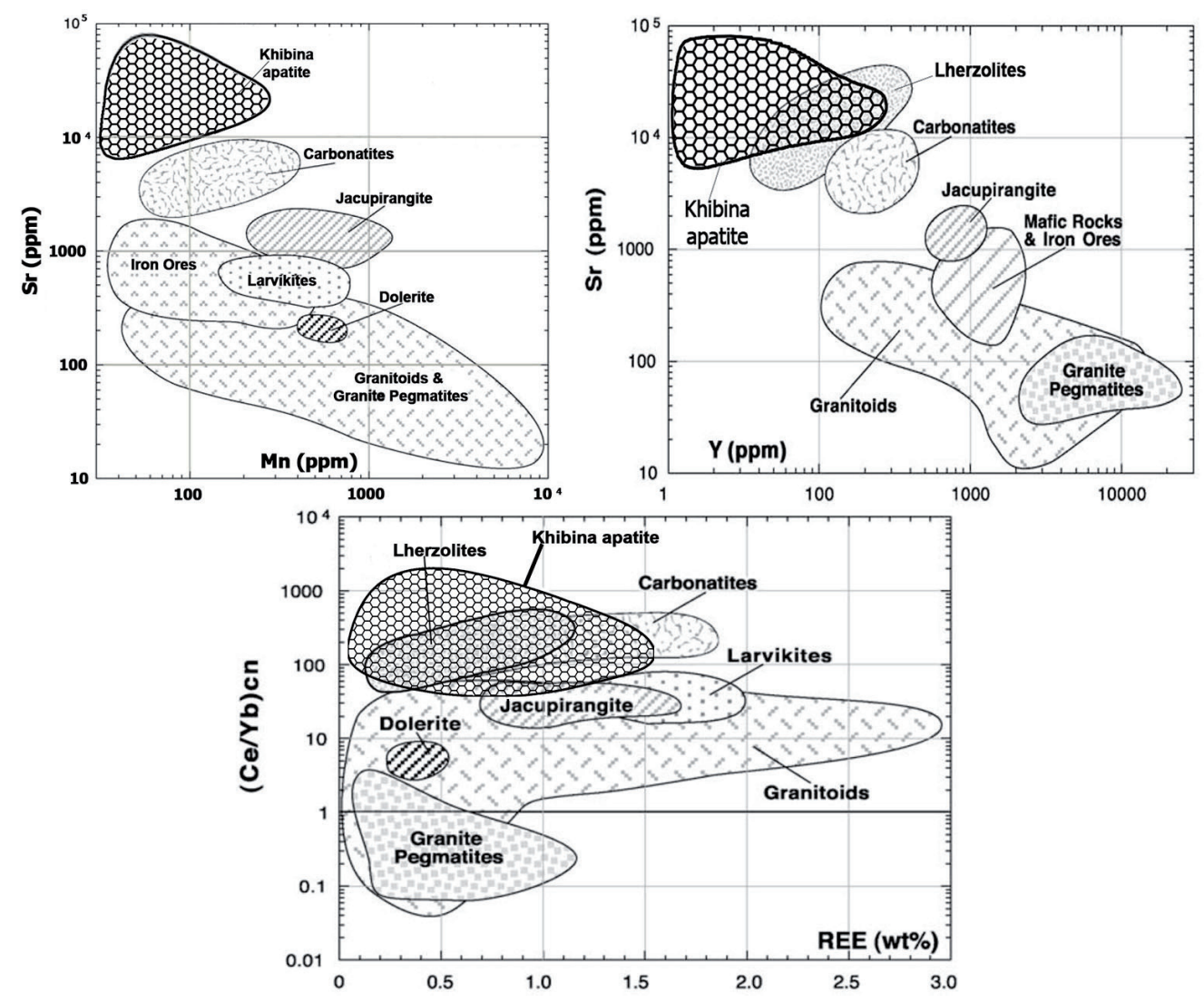

Рис. 1. Композиционное поле апатита Хибины на дискриминантных диаграммах, (Belousova et al., 2002).

Fig. 1. Field of the Khibiny apatite composition on the discriminant diagrams proposed, (Belousova et al., 2002).

Крупнейшее в мире месторождение апатита связано с агпаитовыми нефелиновыми сиенитами Хибинского массива (Кольский полуостров) (Иванова и др., 1970; Зак и др., 1972, Елисеев, 1937). Хибинский массив представляет собой серию кольцевых интрузий, состав которых варьирует в пределах нефелиновых сиенитов за исключением ийолит-уртитового комплекса, включающего апатитнефелиновое месторождение (Arzamastsev et al., 2008). На основании детальных исследований состава апатита различных месторождений ийолит-уртитового комплекса (около 1200 анализов) (табл. 1) были выведены средние содержания РЗЭ в апатитах. Главным методом анализа апатита была лазер-

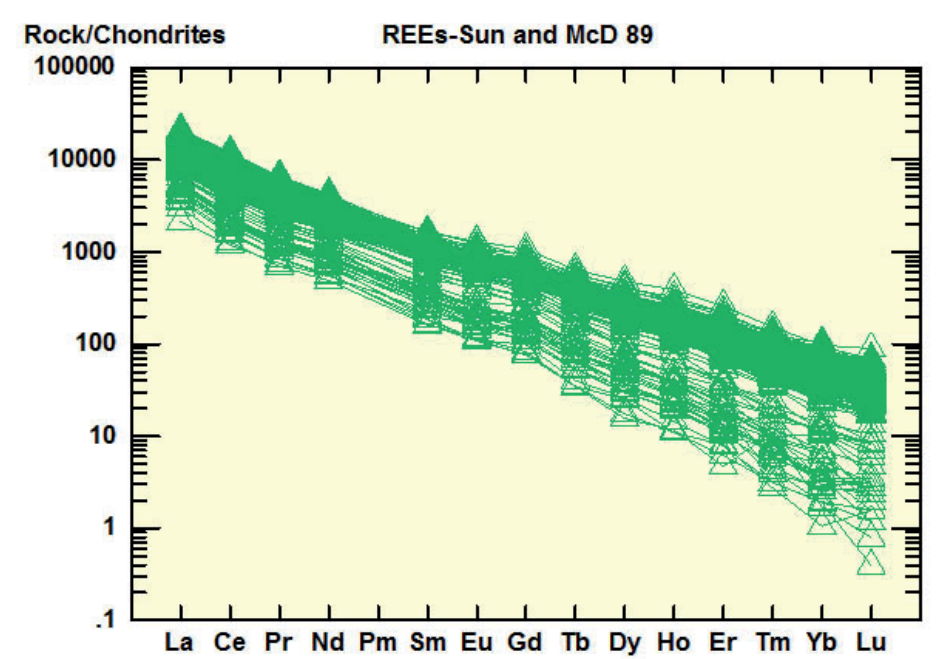

Рис. 2. Распределение РЗЭ в хибинском апатите.

Fig. 2. Distribution of REE in the Khibiny apatite. ная абляция (ICPMS in situ) и микрозондовый (CAMECF 100). Было показано, что, согласно последним данным по номенклатуре апатита (Pasero et al., 2010) в апатито-нефелиновых рудах развит не стронциевый апатит, как это было предположено ранее (Chakhmouradian et al., 2002), а фтор-апатит.

Хибинский фторапатит обладает исключительно высоким содержанием стронция - в среднем $3.85 \%$ (рис. 1) (табл. 1).

Среднее содержание суммы редких земель в исследованном фторапатите составило 8891 ррm.

Учитывая огромные запасы апатито-нефелиновых руд Хибин, мож- 
но заключить, что Хибинские руды представляют собой довольно крупное месторождение редких земель порядка нескольких миллионов тонн суммы редкоземельных металлов. Во всех апатитах содержания легких редких земель значительно преобладают над тяжелыми Р3Э (рис. 2). Среднее значение $\mathrm{Ce} / \mathrm{Yb}=682$. Все исследованные хибинские апатиты не имеют ни положительной, ни отрицательной европиевой аномалий, что характерно для всех пород и минералов Кольской щелочно-карбонатитовой провинции (Downes et al., 2005).

Наши результаты показали заметные различия содержания редкоземельных металлов в апатитах из различных Хибинских месторождений. Особенно высокие концентрации редкоземельных металлов отмечается в апатитах месторождения Коашва-12979 ppm. В то время как в месторождениях Юкспор, Расвумчорр, Олений ручей суммарное содержание редких земель варьирует незначительно 7200-7400 ppm. Интересно отметить, что в апатитах Коашвинского месторождения отмечены самые высокие содержания стронция (табл. 1).

Таблица 1. Примеры распределения элементов в апатитах различных месторождений Хибинского массива (ppm, 1200* анализов).

Table 1. Examples of the distribution of elements in apatites of various fields of the Khibiny massif (ppm, 1200* analyses).

\begin{tabular}{|c|c|c|c|c|c|}
\hline & $\begin{array}{l}\text { Расвумчорр } \\
\text { (38 образцов) }\end{array}$ & $\begin{array}{c}\text { Олений Ручей } \\
\text { (43 образца) }\end{array}$ & $\begin{array}{c}\text { Коашва } \\
\text { (62 образца) }\end{array}$ & $\begin{array}{c}\text { Юкспорр } \\
\text { (12 образцов) }\end{array}$ & $\begin{array}{c}\text { Хибинский } \\
\text { массив }\end{array}$ \\
\hline Элементы & Среднее & Среднее & Среднее & Среднее & Среднее \\
\hline $\mathrm{Ce} / \mathrm{Yb}$ & 441 & 705 & 940 & 416 & 682 \\
\hline$\Sigma \mathrm{REE}$ & 7451 & 7379 & 12979 & 7218 & 8891 \\
\hline $\mathrm{Ce}$ & 3334 & 3283 & 6086 & 3202 & 4040 \\
\hline $\mathrm{La}$ & 2294 & 2247 & 4293 & 2152 & 2799 \\
\hline Pr & 314 & 308 & 521 & 309 & 367 \\
\hline $\mathrm{Nd}$ & 1085 & 1101 & 1637 & 1111 & 1243 \\
\hline $\mathrm{Sm}$ & 150 & 157 & 182 & 156 & 162 \\
\hline $\mathrm{Eu}$ & 41 & 44 & 45 & 45 & 44 \\
\hline $\mathrm{Gd}$ & 113 & 120 & 117 & 122 & 118 \\
\hline $\mathrm{Tb}$ & 13 & 14 & 12 & 14 & 13 \\
\hline Dy & 62 & 64 & 52 & 64 & 60 \\
\hline Ho & 10 & 10 & 8.3 & 10 & 9.8 \\
\hline Er & 21 & 21 & 16 & 21 & 20 \\
\hline $\mathrm{Tm}$ & 2.2 & 2.0 & 1.5 & 2.0 & 1.9 \\
\hline $\mathrm{Yb}$ & 10 & 10 & 7.0 & 9.3 & 8.9 \\
\hline $\mathrm{Lu}$ & 1.0 & 1.0 & 0.7 & 1.0 & 0.9 \\
\hline $\mathrm{Si}$ & 1123 & - & - & - & 1123 \\
\hline $\mathrm{Na}$ & 1100 & - & 1200 & - & 1150 \\
\hline $\mathrm{Sr}$ & 30149 & 30543 & 64771 & 18947 & 38520 \\
\hline $\mathrm{Hf}$ & 0.02 & - & 0.1 & 0.1 & 0.1 \\
\hline $\mathrm{Ta}$ & 0.003 & - & 0.1 & 0.1 & 0.0 \\
\hline $\mathrm{Pb}$ & 1.4 & - & 1.0 & 1.4 & 1.2 \\
\hline Th & 19 & - & 23 & 25 & 22 \\
\hline $\mathrm{U}$ & 2.0 & - & 1.3 & 2.5 & 1.8 \\
\hline $\mathrm{Mg}$ & - & 4181 & 22 & 58 & 2225 \\
\hline $\mathrm{Sc}$ & 0.04 & 3 & 0.6 & 1.2 & 1.6 \\
\hline $\mathrm{Mn}$ & 150 & 157 & 114 & 136 & 142 \\
\hline $\mathrm{Fe}$ & 88 & 313 & 89 & 99 & 182 \\
\hline $\mathrm{Y}$ & 283 & 265 & 171 & 277 & 245 \\
\hline $\mathrm{Zr}$ & 2.3 & 8 & 7.2 & 7.1 & 6.6 \\
\hline $\mathrm{Nb}$ & 0.1 & 1 & 0.6 & 0.1 & 0.4 \\
\hline $\mathrm{Ba}$ & 331 & 418 & 318 & 326 & 363 \\
\hline $\mathrm{Zn}$ & 0.4 & - & - & - & 0.4 \\
\hline
\end{tabular}


Таблица 2. Распределение редких элементов в отходах Апатитового рудника.

Table 2. Distribution of rare elements in the Apatite mine wastes.

\begin{tabular}{|c|c|c|c|c|}
\hline Элементы & $\begin{array}{c}\text { Отходы } \\
\text { апатитовог } \\
\text { рудника 1 }\end{array}$ & $\begin{array}{c}\text { Отходы } \\
\text { апатитового } \\
\text { рудника 1 }\end{array}$ & $\begin{array}{c}\text { Отходы } \\
\text { апатитового рудника 2 } \\
\text { более ранние }\end{array}$ & $\begin{array}{c}\text { Апатит, среднее } \\
\text { (315 анализов) }\end{array}$ \\
\hline $\mathrm{La}$ & $342-76$ & $300-18$ & $191-05$ & $2785-97$ \\
\hline $\mathrm{Ce}$ & $593-25$ & $506-51$ & $339-32$ & $4019-58$ \\
\hline $\mathrm{Pr}$ & $63-02$ & $57-97$ & $40-12$ & $364-95$ \\
\hline $\mathrm{Nd}$ & $209-84$ & $199-49$ & $139-3$ & $1240-18$ \\
\hline $\mathrm{Sm}$ & $34-02$ & $32-08$ & $24-58$ & $162-68$ \\
\hline $\mathrm{Eu}$ & $10-03$ & $9-38$ & $6-74$ & $44-28$ \\
\hline $\mathrm{Dy}$ & $15-88$ & $16-04$ & $12-88$ & $60-43$ \\
\hline $\mathrm{Ho}$ & $2-9$ & $2-95$ & $2-32$ & $9-77$ \\
\hline $\mathrm{Tm}$ & $0-78$ & $0-82$ & $0-67$ & $1-95$ \\
\hline $\mathrm{Yb}$ & $4-29$ & $4-27$ & $3-34$ & $8-88$ \\
\hline $\mathrm{Lu}$ & $0-55$ & $0-47$ & $0-48$ & $1-07$ \\
\hline $\mathrm{Ce} / \mathrm{Yb}$ & $138-29$ & $118-62$ & $101-59$ & $452-66$ \\
\hline
\end{tabular}

Высокие содержания стронция и редких земель в Хибинских апатитах свидетельствует об остаточном характере щелочной магмы. Отсутствие европиевой аномалии является следствием характера первичной магмы щелочно-карбонатитовой формации Кольского полуострова, дифференциация которой происходит без фракционирования плагиоклаза -главного минерала-концентратора двухвалентного европия (Dunworth et al., 2001).

Ежегодно из недр Земли извлекается около 100 млрд. тонн полезных ископаемых, в результате добычи и переработки которых, в окружающей природной среде накапливается около 17.4 млрд. т. твердых и жидких отходов. С целью оценки потенциала редкоземельных элементов в отходах крупнейших в мире апатито-нефелиновых месторождений Хибинского массива Кольского полуострова был отобран материал из хвостохранилищ (около 100 проб) твердых отходов апатитонефелиновых фабрик. Впервые был получен материал по распределению всех редких земель в отходах производства апатитовых руд (рис. 3, табл. 2).

За годы эксплуатации месторождений около 1.5 млрд. тонн руды было переработано (более 300 млн. т $\mathrm{P}_{2} \mathrm{O}_{5}$ ). Учитывая, что содержание апатита в руде, поступающей на фабрику 13.5 \%, объем

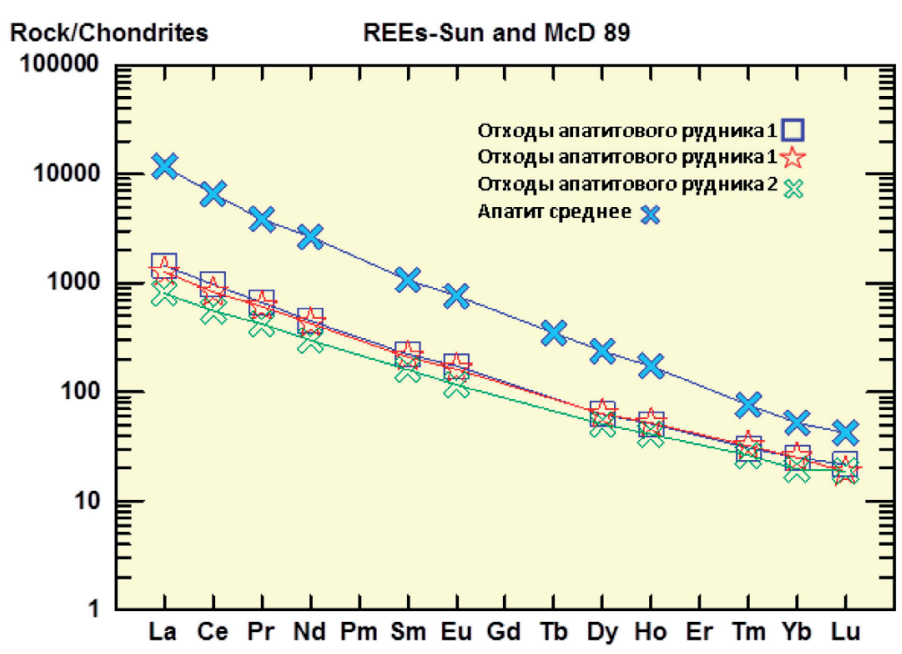

Рис. 3. Распределение редких земель в производственных отходах фабрик апатитовых месторождений.

Fig. 3. Distribution of rare earths in industrial wastes of factories of apatite deposits. пустой породы составит около 1.3 млрд. тонн. На основании полученных данных по содержаниям редких земель общее содержание редкоземельных металлов в отходах составляют около 1.18 млн. т., с учетом данных (Zhirov et al., 2019; 10. КАДАСТР отходов горно..., 1999; Архипов и Решетняк, 2017; Пожиленко и др., 2002; Belousov et al., 2002).

Таким образом, в отходах переработки апатито-нефелиновых руд содержатся довольно высокие содержания редкоземельных металлов. (рис. 3) Сопоставление характера распределения РЗЭ в апатитах и отходах производства показывает существенное различие. Прежде всего, концентрация суммы Р3Э почти на порядок ниже в производственных отходах. Отмечается преобла- 
дание легких редких земель над тяжелыми (рис. 3), но в меньшей степени по сравнению с апатитами. Таким образом, наблюдается фракционирование РЗМ в процессе формирования отходов. Очень важно, что в отходах в большей степени накапливаются более дорогостоящие тяжелые редкие земли. Отношение $\mathrm{Ce} / \mathrm{Yb}$ в отходах значительно ниже $(138,118,101)$, причем чем старше отходы - тем ниже это отношение.

Работа выполнена при финансовой поддержке Программы Президиума РАН І.55П № 01372018-0041.

\section{Литература}

1. Arzamastsev A.A., Yakovenchuk V.N., Pakhomovsky Y.A., Ivanyuk G.Y. The Khibiny and Lovozero Alkaline Massifs: Geology and Unique Mineralization; 33 IGS Excursion, 47; Geological Institute of the Russian Academy of Science: Apatity, Russia. 2008.

2. Belousova E.A., Griffin W.L., O’Reilly S.Y. \& Fisher N.I. Apatites as an indicator mineral for mineral exploration: trace-element compositions and their relationship to host rock type // Journal of Geochemical Exploration. 2002. V. 76. P. 45-69.

3. Chakhmouradian A.R., Reguir E.P., Mitchell R.H. Strontium-apatite: New occurrences, and the extent of Sr-forCa substitution in apatite-group minerals // Can. Miner. 2002. V. 40. P. 121-136.

4. Downes H., Balaganskaya E., Beard A., Liferovich R., Demaiffe D. Petrogenetic processes in the ultramafic, alkaline and carbonatitic magmatism in the Kola Alkaline Province: A review // Lithos. 2005. V. 85. P. 48-75.

5. Dunworth, E.; Bell, K. The Turiy Massif, Kola Peninsula, Russia: Isotopic and Geochemical Evidence for Multisource Evolution // J. Pet. 2001. V. 42. P. 377-405.

6. Pasero M.; Kampf A.R.; Ferraris C.; Pekov I.V.; Rakovan J.; White T.J. Nomenclature of the apatite supergroup minerals // Eur. J. Miner. 2010. V. 22. P. 163-179.

7. Zhirov et al in FODD - Industrial Minerals Book, Lahtinen (ed.). 2019. GTK SP53). P. 35-4.

8. Архипов А.В., Решетняк С.П. Техногенные месторождения. Разработка и формирование. Апатиты: КНЦ PAH. 2017. 175 c. http://www.naukaprint.ru/data/documents/7_arhipov_resh_17.pdf.

9. Елисеев Н.А. Хибинские апатитовые месторождения. ЗВМО. 1937. № 66(3). С. 491-516.

10. Зак С.И., Каменев Е.Л., Минаков Ф.В., Арманд А.Л., Михеичев А.С., Петерсилье И.А. Хибинский щелочной массив. Л.: Недра. 1972. 176 с.

11. Иванова Т.Н., Дудкин О.Б., Козырева Л.В., Поляков К.И. Ийолит-уртиты Хибинского массива / АН СССР. Кольский филиал им. С.М. Кирова. Л-д. Изд-во: Наука. Ленингр. отд-ние. 1970. 179 с.

12. КАДАСТР отходов горно-металлургического производства Мурманской области (по состоянию на 01.01.99 г.) // разработан Горным институтом КНЦ РАН по заказу и с участием Государственного комитета по охране окружающей среды Мурманской области. https://www.murman.ru/ecology/cadastre/.

13. Пожиленко В.И., Гавриленко Б.В., Жиров Д.В., Жабин С.В. Геология рудных районов Мурманской области. Апатиты. Изд-во: КНЦ РАН. 2002. 359 c. http:/geoksc.apatity.ru/images/stories/Print/zhirov/books/ Rug_Geo_Murm.pdf. 